\title{
THEORETICAL AND PRACTICAL ASPECTS OF FLOW CONTROL IN PROGRAMMED-TEMPERATURE GAS CHROMATOGRAPHY
}

\author{
ASPECTOS TEORICOS Y PRACTICOS DEL CONTROL DE FLUJO EN \\ CROMATOGRAFIA GASEOSA A TEMPERATURA PROGRAMADA
}

\author{
F.R. González ${ }^{1}$ A.M. Nardillo ${ }^{2}$
}

\begin{abstract}
SUMMARY
Behavior patterns for the temperature dependence of column head pressure and outlet volumetric flow rate are analyzed for some particular configurations of chromatograph's flow control system. Quantitative prediction of this behavior, and specially it's effect on gas hold up time, is evaluated. The attention is centered on the application to PTGC retention simulation.
\end{abstract}

Keywords: temperature programming; flow control; hold-up time.

\section{INTRODUCTION}

The current methodology for programmed temperature (PT) retention estimation through isothermal data was settled in the early 60 's [1-5]. The starting point is the differential equation of band migration. From general isothermal chromatographic theory:

$$
\frac{\mathrm{dz}}{\mathrm{dt}}=\frac{\mathrm{v}(\mathrm{z})}{(1+\mathrm{k})}
$$

Where $\mathrm{z}$ is the axial variable of cylindrical coordinates which describes the position of solute's peak in the column at time $t$ from injection, $d z / d t$ is the migration rate of solute's peak at $z$ position, $k$ the capacity factor of the column and $v(z)$ is the local carrier gas velocity. Assuming valid D'Arcy's equation as the differential equation of motion for the carrier gas, and the ideal gas equation of state, $v(z)$ can be related to it's isothermal average along the column $\overline{\mathrm{v}}$ by (see for example [6]) :

$$
v(z)=\frac{\bar{v}}{Q(z)}
$$

\footnotetext{
${ }^{1}$ División Quimica Analitica, Facuttad de Ciencias Exactas, Universidad Nacional de La Plata

${ }^{2}$ Miembro de la Cartera del investigador del CONICET; Profesor Asociado. UNLP
} 
Where the local velocity factor $Q(z)$ is:

$$
\mathrm{Q}(\mathrm{z})=(3 / 2) \frac{\left(\mathrm{P}^{2}-1\right)}{\left(\mathrm{P}^{3}-1\right)}\left[\mathrm{P}^{2}-(\mathrm{z} / \mathrm{L})\left(\mathrm{P}^{2}-1\right)\right]^{1 / 2}
$$

$P$ is column's inlet/outlet pressure ratio, $P_{i} / P_{0}$.

So far, we were involved with isothermal conditions, being $(z, t)$ the variables of differential eq. (1). In programmed temperature there is a defined relationship between variable $t$ and the absolute temperature $T$, fixed by the operator as an explicit function: $T=f(t)$. We shall use the notation: $d T / d t=f$ ' $(T)$. The configuration of the flow control system will define how column's head pressure will evolve with temperature, namely defining a certain $P(T)$. The characteristics of this function for some types of flow control is a central topic of this paper. So, in PT eq. (3) shows that $Q$ is dependent as $Q(z, T)$. Obviously, $\bar{v}$ is a function only of $P(T)$ for a given column.

Changing variable $t$ by $T$, replacing $v(z)$ in (1), and attending that gas hold-up time is $t_{0}(T)=L / \bar{v}(T)$, where $L$ is column's length, the differential eq. of peak motion in PTGC becomes:

$$
\frac{d z}{d T}=\frac{L}{f^{\prime}(T) Q(z, T) t_{M O}(T)[I+k(T)]}
$$

As shown, estimation of retention parameters in PTGC means dealing with two general aspects: with thermodynamics as $T$ affects $k(T)$, and fluid dynamics, involving the behavior of $P(T)$, and so conditioned by the gas flow control. Two special types of flow control have been most commonly treated in the literature related to PTGC retention: constant mass flow $[2,4]$, and constant pressure drop along the column $[4,6]$. Less attention has been given to other widely applied flow control devices, such as mechanical controllers consisting in a needle valve and diaphragm operated valve in serial array, and more recently developed electronic head pressure programmable chromatographs.

Integration of eq. (4)can be carried out considering this a summation of sequential isothermal states, or in other words, assuming thermal equilibrium for each integrating point (Thermal equilibrium during practical temperature programming has been questioned [7,8]). This is the fundamental hypothesis of the theory in addition to those implicit in (1) and (3). It can be shown [9] from eq. (4) that:

$$
1=\int_{T^{0}}^{T_{R}} \frac{d T}{f^{\prime}(T) t_{0}(T)[1+k(T)]}
$$

Where $T^{0}$ and $T_{R}$ are the initial temperature of the program and solute's retention temperature, respectively. Solving (5) for a certain system implies that $t_{0}(P(T))$ and $k(T)$ should be attainable for this. The ultimate goal of this work is to develop, for the studied systems, analytical expressions of $t_{0}(T)$, as function of accessible parameters so the integrand of eq.(5) can be explicited 
The endeavor of taking approximations of different nature, with the aim to simplify the solution of the integral equation, has been a constant that signed PTGC simulation development from it's beginnings [1-3, 10, 11]. Present universally available computation facilities makes many of them now unnecessary. Nevertheless, a contemporary common practice among simulation procedures is to linearize the temperature dependence of $t_{0}[6,11]$, approximation that would be suitable only for special situations, as will be shown. In other cases $t_{0}$ has been approximated as constant with temperature [12-14].

\section{EFFECTS OF TEMPERATURE ON GAS HOLD-UP TIME}

The objective of this section is to settle a general expression of $t_{0}$ as a function of $P(T)$, valid for capillary or packed columns.

Integrating D'Arcy's equation along the column and by applying Continuity equation $[15,16]$ to the ideal gas, the following relationship may be stated between the volumetric flow rate at the outlet of the column $F_{0}(T)$, viscosity of the carrier gas $\eta(T)$ and $P(T)$, all measured at column's temperature T [15]:

$$
2 \frac{\mathrm{L}}{\mathrm{ABP}_{0}} \mathrm{~F}_{0}(\mathrm{~T}) \eta(T)=\left[\mathrm{P}^{2}(\mathrm{~T})-1\right]
$$

where $\mathrm{A}$ is the cross sectional area of the empty column and B the permeability (see for example [17,18]). Thermal expansion of materials is known to exert a very small effect and for practical purposes the factor $L /(A B)$ may be taken as constant with temperature. The verisimilitude of this assumption is discussed in the following section. Then, if eq. (6) is divided by the same expression applied to a initial or reference condition and $P_{0}$ is held constant

$$
\frac{\mathrm{F}_{0}(\mathrm{~T}) \eta(\mathrm{T})}{\mathrm{F}_{0}^{0} \eta^{0}}=\frac{\left[\mathrm{P}^{2}(\mathrm{~T})-1\right]}{\left[\mathrm{P}^{0^{2}}-1\right]}
$$

where $\mathrm{F}_{0}^{0}$ is the outlet volume flow rate at reference condition $\left(\mathrm{T}^{0}, \mathrm{P}^{0}\right)$. From here forth, the superindex 0 will denote reference or initial condition for any variable. The temperature dependence of gas viscosity, in the range of chromatographic interest, can be written as $[15,19]$ :

$$
\eta(T)=C_{G} T^{N}
$$

Exponent $\mathrm{N}$ is 0.725 for nitrogen, 0.646 for helium and 0.680 for hydrogen [19]. By applying (8), (7) turns to:

$$
F_{0}(T)=\left(C_{c} T^{-N} P_{0}\right)\left[P^{2}(T)-1\right]
$$

where column's "flow rate constant" $\mathrm{C}_{\mathrm{c}}$ is: 


$$
C_{c}=\frac{F_{o}^{0} 0^{0^{N}}}{\left(P^{0^{2}}-1\right) P_{0}}
$$

Replacing $\mathrm{F}_{0}^{0} /\left(\mathrm{P}^{0^{2}}-1\right)$ as given by $(6)$ and $\mathrm{T}^{0^{\mathrm{N}}}$ by $(8)$, reveals the physical meaning of the constant:

$$
\mathrm{C}_{\mathrm{c}}=\frac{\mathrm{AB}}{2 \mathrm{LC} \mathrm{C}_{\mathrm{G}}}
$$

For a given packed column at constant temperature and mass-flow $B / C_{G}$ is inversely proportional to Blake-Kozeny's friction coefficient which is a factor that determines the irreversible conversion of mechanical energy into heat, the so called frictional loss [16]. The constant is a flow property of combined column and gas .

If temperature and outlet pressure are held constant, according to eq.(9) $F_{o}$ should be a straight line passing through the origin when plotted against the adimensional variable $\left(P^{2}-1\right)$, being the slope $\left(\mathrm{C}_{\mathrm{c}} \mathrm{T}^{-\mathrm{N}} \mathrm{P}_{\mathrm{o}}\right)$. This is actually a procedure that can be followed to obtain $\mathrm{C}_{\mathrm{c}}$, as an alternative to the application of eq.(10).

Equation (9) is applicable either to packed or capillary columns connected to any kind of flow control, as it was derived considering the column individually. Thus, if flow parameters are measured at a reference or initial condition, as routinely do chromatographers, is imperative to know how $P$ evolves with temperature to enable the prediction of flow rate as a function of temperature, and viceversa. The evolution of $P(T)$ will depend upon the configuration of the system upstream the column.

A similar reasoning can be followed for $t_{0}$. According to the classical isothermal chromatographic theory, the dead volume of the column at temperature $\mathrm{T}$ can be evaluated by: $V_{0}(T)=F_{0}(T) j(T) t_{0}(T)$. Applying this to a reference condition, dividing both expressions, neglecting thermal dependence of void volume and eliminating flow rate by using (9), leads to the final expression we were seeking:

$$
t_{0}(T)=\left(C_{t} T^{-N} P_{o}\right)^{-1} \frac{\left[P^{3}(T)-1\right]}{\left[P^{2}(T)-1\right]^{2}}
$$

where the "dead time constant" is:

$$
\mathrm{C}_{\mathrm{t}}^{-1}=\mathrm{t}_{0}^{0} \frac{\left(\mathbf{P}^{0^{2}}-1\right)^{2} \mathbf{P}_{\mathrm{o}}}{\left(\mathbf{P}^{0^{3}}-1\right) \mathrm{T}^{0^{N}}}
$$

The relationship between column's constants, can be derived by applying the solution (32) from reference [20]:

$$
C_{t}=\frac{3 C_{C}}{2 V_{0}}
$$


The same considerations of (9) can be formulated for (12), standing out the fact that the only hypothesis added, to those already accounted for (4), is the insignificance of changes in column's geometric parameters $\mathrm{L} / \mathrm{AB}$ and $\mathrm{V}_{0}$ due to thermal expansion.

\section{THERMAL EXPANSION EFFECTS}

For a packed column can be shown, from basic definitions [18,21], considering negligible the contribution of liquid phase respect to solid support, that thermal expansion will generate a relative change in total porosity $\varepsilon$ according to:

$$
\frac{1-\varepsilon(T)}{1-\varepsilon^{0}}=\left[\frac{1+3 \alpha_{S}\left(T-T^{0}\right)}{1+3 \alpha_{w}\left(T-T^{0}\right)}\right] \equiv D
$$

being $\alpha_{w}$ tube's wall linear thermal expansion coefficient, and $\alpha_{s}$ that of solid support. Assuming that the interparticle porosity $\varepsilon_{\mathrm{u}}$ is a constant fraction $u$ of total porosity, and calculating the permeability B of the packed column through Carman-Kozeny's equation:

$$
\frac{B(T)}{B^{0}}=\left[1+\alpha_{s}\left(T-T^{0}\right)\right]^{2}\left[\frac{1-D\left(1-\varepsilon^{0}\right)}{\varepsilon^{0}}\right]^{3}\left[\frac{1-u \varepsilon^{0}}{1-u\left[1-D\left(1-\varepsilon^{0}\right)\right]}\right]^{2}
$$

With assumptions so far displayed, relative temperature changes in column's interstitial void volume, the space where convective gas transport occurs, is evaluable by:

$$
\frac{V_{0}}{V_{0}^{0}}=\left[\frac{1-D\left(1-\varepsilon^{0}\right)}{\varepsilon^{0}}\right]\left[1+3 \alpha_{w}\left(T-T^{0}\right)\right]
$$

We must be bewared that, although eqs.(15-17) are applicable to global quantities, if thermal expansion effects would be significant in packed columns, the homogeneity of this must be affected. If the wall expands much more than the packing, the "extent of wall region" [22], that is the region where homogeneousness of the packing is disturbed by the presence of the wall, should be increased. Channeling near the wall could be expected and a consequent anomalous behavior of the column, with a diminished pressure drop respect to a well packed one. The most disadvantageous condition, where thermal expansion coefficients differ significantly, is that when tube's wall is metallic, being the packing usually a siliceous material. In Table 1 are shown relative values of porosity, permeability, $(\mathrm{L} / \mathrm{AB})$ ratio and interparticle void volumes as a function of the temperature interval, calculated using eqs.(15-17) with reported values of expansion coefficients, specified initial porosity and $u$, assuming that the wall is made of stainless-steel.

Expected effect of thermal expansion on the described parameters is very poor, at a point that would be difficult to evaluate experimentally. An early attempt of estimation was conducted through volumetric measurements [15], but what can be stated a priori is that the experimental error would be within the order of the greatest changes in the parameters to be monitored. 


\section{Table 1}

Relative change of column geometric parameters as a function of temperature interval according to Eqs. (15-17) considering a porous solid support packing

\begin{tabular}{|ccccc|}
\hline$\left(\mathrm{T}-\mathrm{T}^{0}\right)$ & $\varepsilon / \varepsilon^{0}$ & $\mathrm{~B} / \mathrm{B}^{0}$ & $(\mathrm{~L} / \mathrm{AB})$ rel. & $\mathrm{V}_{0} / \mathrm{V}^{0}$ \\
50 & 1.0002 & 1.0020 & 0.9971 & 1.0027 \\
100 & 1.0005 & 1.0041 & 0.9943 & 1.0054 \\
150 & 1.0007 & 1.0061 & 0.9915 & 1.0081 \\
200 & 1.0010 & 1.0081 & 0.9887 & 1.0108 \\
250 & 1.0012 & 1.0101 & 0.9859 & 1.0135 \\
\hline
\end{tabular}

If flow in a capillary column is approximated by Hagen-Poiseulle's equation (valid for incompressible fluids) the permeability may be estimated as: $B=d_{c}{ }^{2} / 32$, where $d_{c}$ is the internal diameter of the column [18]. With this consideration can be shown that expected thermal effects on $\mathrm{L} / \mathrm{AB}$ and $\mathrm{V}_{0}$ in a capillary are even lower than those taking place in a packed column.

\section{FLOW CONTROL}

In this section we shall analyze the behavior of $t_{0}(T)$ in four different types of flow control, contrasting predicted curves with experimental data .

\section{Experimental}

All system's common monitored physical observables are:

a) Column's outlet absolute pressure $P_{0}$. Here will be invariably the atmospheric pressure measured with a Fortin's design barometer.

b) Column's manometric inlet pressure $P_{i}$. This was measured by a mercurial column manometer, in the case of low pressure drop columns, and with a Bourdon's tube needle manometer for high ones.

From this two data the absolute head pressure $P_{i}$ and $P$ was readily acquainted for any column temperature.

c) Column's outlet volume flow-rate. This was measured at ambient temperature with a bubble flowmeter. Gas reaching ambient temperature was ensured interposing between the detector's outlet and the flowmeter a $6 \mathrm{~m}$ long $1 / 4$ " coiled copper tube as a heat exchanger. Pressure drop along the exchanger was calculated through standard procedures [16] and found to be in the order $10^{-2} \mathrm{mmHg}$, being completely negligible. Measured flow rate was corrected by water vapor saturation at the flowmeter and by temperature according to: 


$$
F_{0}(T)=F_{\text {meas }} \frac{T}{T^{0}} \frac{\left(P_{0}-P_{w}\right)}{P_{0}}
$$

where $P_{w}$ is water vapor pressure at ambient temperature $T^{0}$.

d) Gas hold-up time $t_{0}(T)$. This was determined using methane as the unretained solute. As different chromatographs were employed, data are given with two different precision levels of $10^{-2}$ and $10^{-3} \mathrm{~min}$. Detection was carried out with FID detectors in all cases.

The oven, temperature control and record/integrator of two chromatographs were used alternatively, a Hewlett Packard 5880 and a Konik 3000 .The original flow control from the chromatograph was disassembled in order to rebuild it according to each studied configuration.

Nitrogen was used as the carrier and test gas in all cases.

Further experimental details will be given for each studied system.

\section{The needle valve flow control}

Needle valve in itself does not have much importance as a flow control device. The importance stems from the fact that it's theoretical description is necessary for treating more complicated mechanisms, since it is a basic accessory of pneumatic systems. Probably for a long time the most widely applied devices have been the mechanical flow controllers consisting in a needle valve in serial array with a diaphragm operated valve, all machined in the same body [23]. In a forthcoming paper we shall intend an evaluation of systems containing it. For doing that, the first step to take is the description of thermal evolution of a system containing only one isothermal restriction (valve) connected to a temperature variable resistance to flow (column), as we do in this section. The needle valve system is the simplest device to provide a predictable non-linear head pressure program, as will be shown.

The configuration of flow control to be analyzed is the one contained in the scheme of Figure 1 . The first device present in the gas stream is the pressure regulator A, currently connected directly to the high pressure supply tank. It's function is to ensure a constant selectable absolute pressure $P_{1}$ at the inlet of needle valve $B$. The chosen reference condition, for sake of simplicity, will be when all the system, included the oven, is at ambient temperature $\mathrm{T}^{0}$.

1. Valve's equation. The first task will be to obtain a relationship between the flow rate at plane " 2 ", $F_{2}$, when the oven is at temperature $T$, and the actual pressure drop in valve B. For doing that we shall apply the Macroscopic Mechanical Energy Balance [16] to planes "1" and "2", making the following hypothesis :1) Steady state. 2) Laminar flow. 3) Ideal gas. 4) Velocity profiles across tubing connections can be approximated by solution of NavierStokes eq. [16], considering that pressure drops along them are small, compared to those in the valve and column; in this case the cross sectional averages of gas velocity hold the relationship: $\left\langle\mathrm{v}^{3}\right\rangle /\langle\mathrm{v}\rangle=2\langle\mathrm{v}\rangle^{2}$. 5) Fanning's friction coefficient is calculated applying the arithmetic averages, between valve's inlet and outlet, to parameters present in Reynold's 
number. 6) Considering negligible, in current chromatographic conditions, the kinetic energy difference per unit mass-flow term, respect to the other terms of the macroscopic mechanical energy balance. 7) Applying Continuity equation of the ideal gas to arithmetic average quantities in the valve and plane " 2 ": $\overline{\mathrm{P}} \frac{\overline{\langle v}\rangle}{\langle\mathrm{P}}=\mathrm{P}_{2}\langle\mathrm{v}\rangle_{2}$.

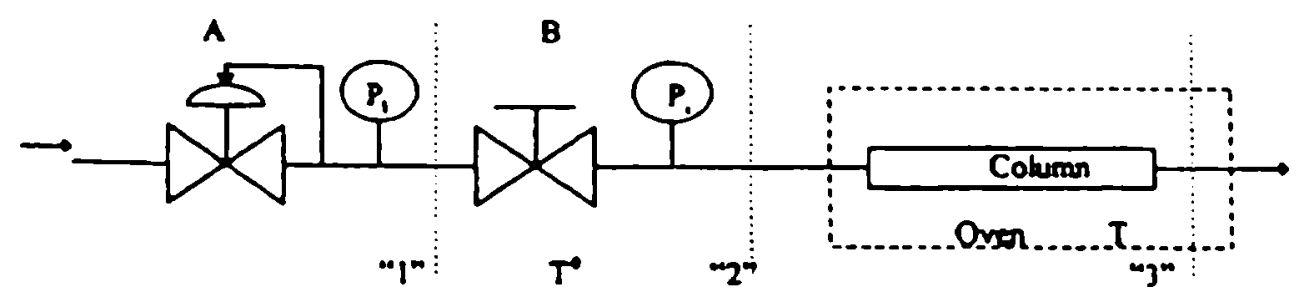

Fie. 1.- Scheme of the stodied needle valve tow control sysiem A is a pressure regulator and

$B$ is the needle valve. Valve inlet pressure is $P_{1}$.

With the described hypothesis, the mactoscopic balance leads to:

$$
\mathrm{F}_{2}=\left(\mathrm{C}_{\mathrm{v}} \mathrm{T}^{0^{-\mathrm{N}}} \mathrm{P}_{2}\right)\left[\left(\frac{\mathrm{P}_{1}}{\mathrm{P}_{2}}\right)+1\right]^{2} \ln \left(\mathrm{P}_{1} / \mathrm{P}_{2}\right)
$$

where $T^{0}$ is valve's temperature (ambient), selected as reference, and $C_{v}=C / C_{G}$. This is the valve equation. The constant $\mathrm{C}_{\mathrm{v}}$ depends not only on the design and opening of the valve, through geometric parameters contained in $C$, but with the constant $\mathrm{C}_{\mathrm{G}}$ of the carrier gas being used. Eq. (18) is of the same type of (9) and (12), although it was derived from a different formalism than the integration of D'Arcy's eq., valve constant plays an equivalent role as column's constant $\mathrm{C}_{\mathrm{C}}$

We must be bewared that as pressure drop in the valve increases, velocity and pressure profiles bends along it, departing the arithmetic averages (hypothesis 5) from the correct ones calculated through the hypothetical exact fluid dynamic solution. In chromatographic conditions the inlet / outlet pressure ratio in the valve would rarely exceed 2 or 3 .

2. Systems equation. The second task is to study the system as a whole, to determine how it will evolve varying the temperature of the oven. When the column is connected to the valve in the chromatograph's flow control system, as was illustrated in the scheme of Figure 1 , then $P_{i}(T) \equiv P_{2}(T)$. For a given oven temperature the flow rate at " 2 ", $F_{2}$, can be related to the flow rate at plane " 3 ", i.e. $F_{0}(T)$, accounting that mass flow is constant in steady state. Consequently, using Continuity eq. and the Ideal Gas eq.

$$
F_{0}(T)=\left(\frac{T}{T^{0}}\right)\left(\frac{P_{i}}{P_{o}}\right) F_{2}
$$

$F_{0}(T)$ can be described also by column's eq.(9). Replacing (9) and (18) in (19) and rearranging: 


$$
\frac{\left(\frac{P_{i}}{P_{0}}\right)^{2}-1}{\left(\frac{P_{i}}{P_{0}}\right)^{2}\left[\left(\frac{P_{1}}{P_{i}}\right)+1\right]^{2} \ln \left(P_{1} / P_{i}\right)}-C_{s}\left(\frac{T}{T^{0}}\right)^{1+N}=0
$$

where the constant of the system is: $C_{s}=C_{v} / C_{c}$. Contrary to column's and valve's constants, $\mathrm{C}_{\mathrm{s}}$ results independent of the parameter of the gas, depending only on geometric parameters of valve and column.

If selected $P_{1}$ and $P_{0}$ remain constant through programmed temperature, then eq. (20) defines a implicit function of $P_{i}$ in terms of $C_{s}$ and the actual reduced temperature: $G\left(P_{i}, T\right)=0$. This can be solved numerically by a trial and error algorithm of iterative approximations. System's constant can be evaluated from initial head pressure applying (20):

$$
C_{s}=\frac{P^{0^{2}}-1}{P^{0^{2}}\left[\left(\frac{P_{1}}{P_{i}^{0}}\right)+1\right]^{2} \ln \left(P_{1} / P_{i}^{0}\right)}
$$

3. Experimental corroboration of valve's equation. This implies testing the valve individually, separated from the column. If eq.(18) correctly describes the flow rate at the outlet of the valve, this plotted as a function of the adimensional variable $\left[\left(P_{1} / P_{2}\right)+1\right]^{2} \ln \left(P_{1} / P_{2}\right)$ should provide a straight line passing through the origin with slope $\left(C_{v} T^{-N} P_{2}\right)$, when valve's temperature and outlet pressure remain constant .In Figure 2, curve 1 , is presented the experimental behavior of a Brooks Instrument's needle valve (model $8504 \mathrm{~A}$ ) at constant ambient temperature. The outlet was connected directly to the flowmeter at the atmospheric pressure, so: $P_{2}=P_{0}=$ const. The inlet was connected to a pressure regulator. Note that the flow range longly exceeds that normally encountered in $G C$.

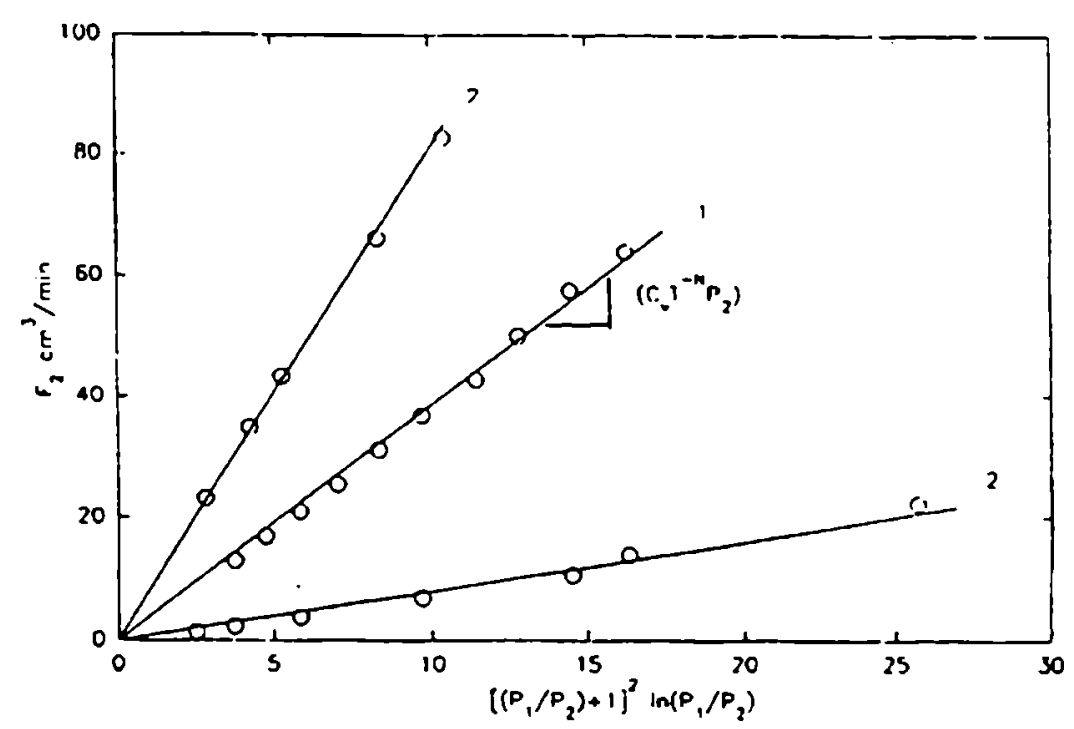

Fig. 2- Outlet nitrogen now-rate of a needle valve (plot 1) and a seat valve (plots 2) as a function of absolute inlet pressure. Range of $P_{1}: 1120$ to 2200 mmHg (abs.). Data interpreted by Eq. (18), measured at ambient temperature $\left(T=26^{\circ} \mathrm{C}\right)$ and outlet atmospheric pressure $\left(P_{I}=765\right.$ mmHg). Upper plot 2 belongs to an incremented opening, less than $5^{\circ}$ lomob turn with respect to lower plot 2. 
In order to test the valve eq. with a different design, in the same figure are presented two curves, both identified by number 2 , belonging to a almost closed seat valve. Valve's openings differ only in about a $5^{\circ}$ turn between them .

As a matter of fact, the macroscopic balance (18) would be applicable to any restriction to the flowing gas meeting the basic hypothesis, as it only determines punctual values, making no inference about profiles between control planes. For example, it could be applied to two valves in serial array, or even to a packed bed, considering that the friction factor given by Blake-Kozeny's equation is for our purposes of the same nature of Fanning's factor [16]. As a curiosity in Figure 3 are plotted flow rate measurements for a $200 \mathrm{~cm}$ long column with $2 \mathrm{~mm}$ i.d.., filled with Chromosorb W 80/100 mesh, tested in the same conditions that were valves of Figure 2. Simultaneously are presented the same data interpreted according to integrated D'Arcy's eq. (9). Departures from linearity takes place at about $40 \mathrm{c.c} / \mathrm{min}$ in both representations and deviations are pondered differently. The origin of this phenomena may be conjecturally assigned to an uncontrolled heat build-up due to rising frictional losses, considering that frictional losses per unit mass-flow are in the order $10^{8} \mathrm{~cm}^{2} / \mathrm{s}^{2}$, and the fact that is indifferent to the interpretation formalism. Measurements were taken at ambient temperature without a thermostatic bath.

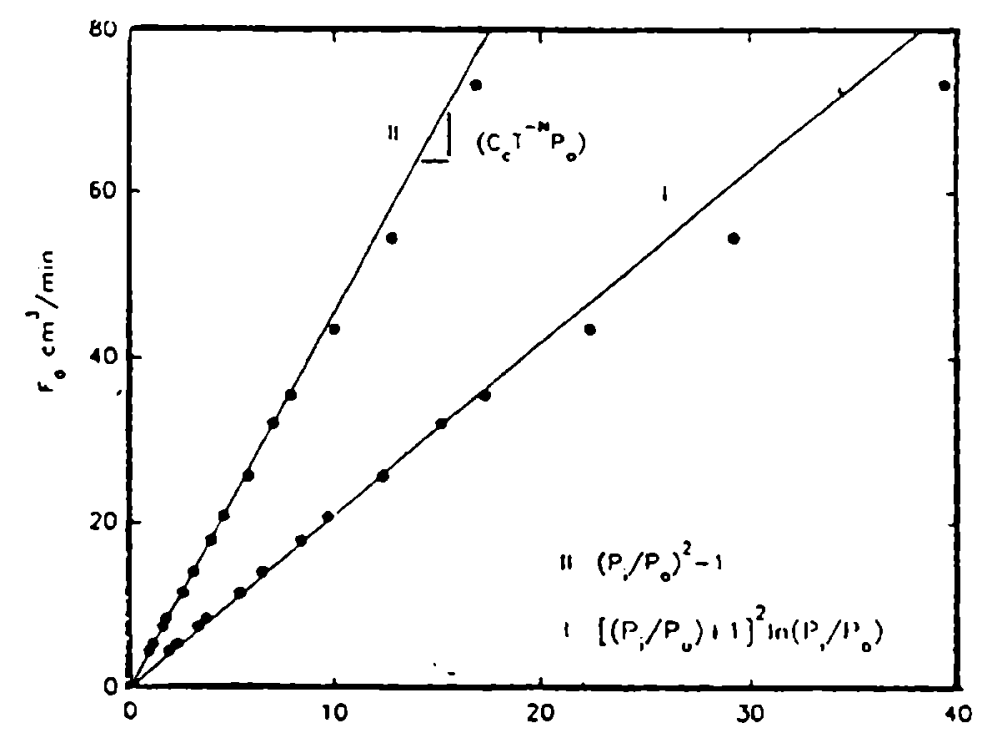

Fig. 3.- Same test as in Fig. 1 with a column $200 \mathrm{~cm}$ long, $2 \mathrm{~mm}$ I.D, filled with Chromosorb $80 / 100 \mathrm{mesh}, 5 \%$ OV-101. T=27 $\mathrm{C}$ and $P_{0}=760 \mathrm{mmHg}$. Plot I: data interpreted by Eq. (18), adimensiomal abscisea is $[P+1]^{2}$ in $P$.

Plot II: data interpreted by Eq. (9), adimensional abscissa is $\left(P^{2}-1\right)$

4. Experimental corroboration of system's equation. Experimental isothermal determinations of volume flow rate were performed at different temperatures with the flow control system illustrated in the scheme of Figure 1, using the needle valve mentioned before. Afterwards, fixing the same initial reference condition $\left(\mathrm{P}_{\mathrm{i}}^{0}, \mathrm{~T}^{0}, \mathrm{~F}_{0}^{0}\right)$, chromatograph's FID detector was turned on and $t_{0}(T)$ were measured. A $2 \mathrm{~m}$ long packed column with $\mathrm{OV}-101$ stationary phase was used. Figure $4 A$ shows the experimental evolution of $P_{i}(T)$, starting from reference at $26^{\circ} \mathrm{C}$, up to 240 . Filled line was calculated by a Basic computer program solving equation (20). As column temperature rises, resistance to flow increases due to rising gas viscosity and $P_{i}$ grows steeply. But since selected $P_{1}$ is constant, pressure drop in valve $B$ is continuously diminishing, reducing consequently the gas supply as indicated by (18)

In Figure 4B calculated and experimental flow rates $F_{0}(T)$ are represented. The predicted behavior obtained by solving equations (20) and (9) is a initial increase, then going through a maximum, and later decay. This is what actually takes place as shown by 
experimental data. In Figure 4C are represented experimental and theoretical behavior of $t_{0}(T)$ (equations (20) and (12)) for the column and conditions mentioned above. One should be alerted that this is not the unique behavior pattern of gas hold-up time for this flow control configuration. Theoretically, if initial conditions are selected adequately, $t_{0}(T)$ can go through a slight minimum, or be a almost linear monotonically increasing function.
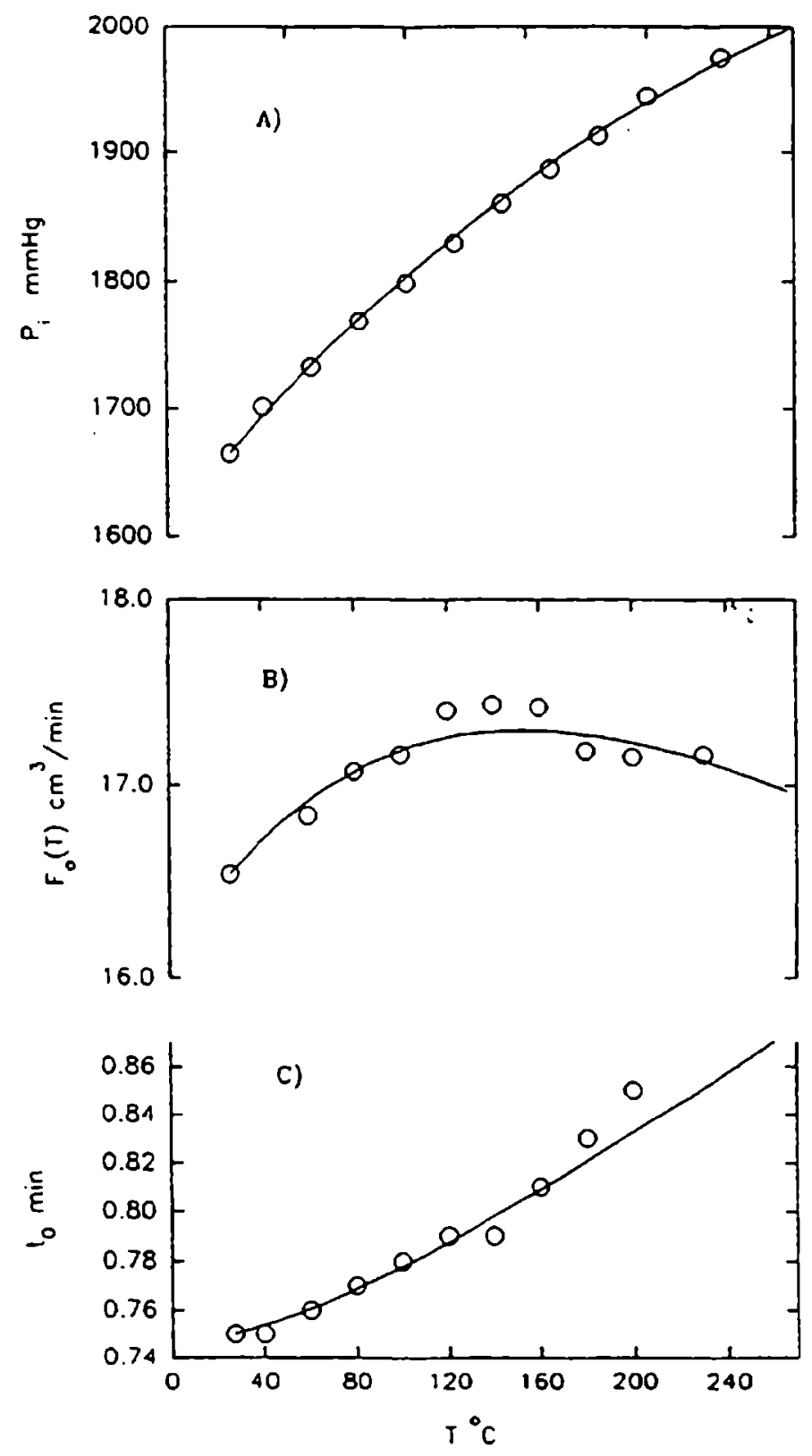

Fig. 4.- Flow functions for the needle valve control system (A) $P_{(}(T)$ function. Colwmn $\approx$ in Fig. 3. $P_{\sigma}=766, P_{1}=2390$ and

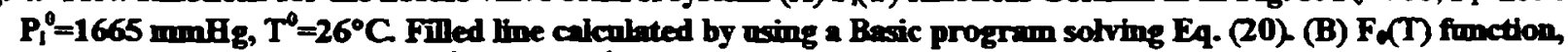
conditions as in (A) and $F_{0}{ }^{6}=16.54 \mathrm{~cm}^{3} / \mathrm{min}$. Filled line calculated by the same program, Eqs $(9,10,20)$.

(C) to fonction, conditions $2 x$ in (A) and $t_{0}^{\circ}=0.75 \mathrm{~min}$ Filled line calculated by Baxic program, Eqs $(12,13,20)$.

\section{The constant head pressure control}

A configuration of mechanical devices generating a constant head pressure on the column is schematically indicated in Figure 5. Pressure regulator A makes a coarse pressure reduction, smoothing operation conditions for the fine tuning regulator $B$, this one assures constant inlet pressure $P_{i}$ through temperature program.

This is a rather trivial case already considered $[4,6]$. If column's outlet pressure is held constant too, from eqs. $(9,10)$ and $(12,13)$ will result: 


$$
\begin{aligned}
& F_{0}(T)=F_{0}^{0}\left(\frac{T}{T^{0}}\right)^{-N} \\
& t_{0}(T)=t_{0}^{0}\left(\frac{T}{T^{0}}\right)^{N}
\end{aligned}
$$

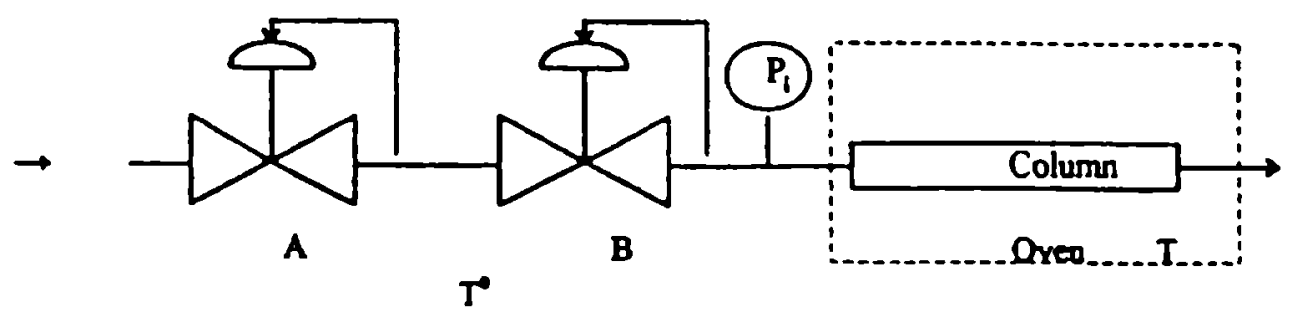

Fig. 5-Scheme of the applied control for generiting a columm constant inlet preasure.

Figure 6 shows the behavior pattern expected for this flow control system. In the particular condition described here one could linearize $t_{0}(T)$ for practical purposes without committing an appreciable error. A $120 \mathrm{~cm}$ column with $5 \%$ OV-17 stationary phase and Gas Chrom Q 80/100 mesh was used in this case .

\section{The constant mass flow control}

We shall consider an idealized device capable to hold constant mass flow during a temperature program. This could be, for example, a electronic microprocessor sensing gas delivery at a constant reference temperature $T^{0}$ by means of a differential hot wire anemometer and commanding a solenoid valve in such a way that flow will remain constant whatever is column's temperature. Electronically drived mechanisms have been described in the literature [24]. If such commitment is attained, then $F_{o}$ measured at $T^{0}$ in a running will be constant and equal to that at initial conditions. Then:

Replacing in (9):

$$
F_{0}(T)=F_{0}^{0} \frac{T}{T^{0}}
$$

$$
P(T)=\left[1+\left(P^{0^{2}}-1\right)\left(\frac{T}{T^{0}}\right)^{1+N}\right]^{/ 2}
$$

And from (12):

$$
t_{0}(T)=t_{0}^{0}\left(\frac{T}{T^{0}}\right)^{-(2+N)} \frac{\left\{\left[1+\left(P^{0}-1\right)\left(\frac{T}{T^{0}}\right)^{(1+N)}\right]^{\beta / 2}-1\right\}}{\left(P^{0^{3}}-1\right)}
$$



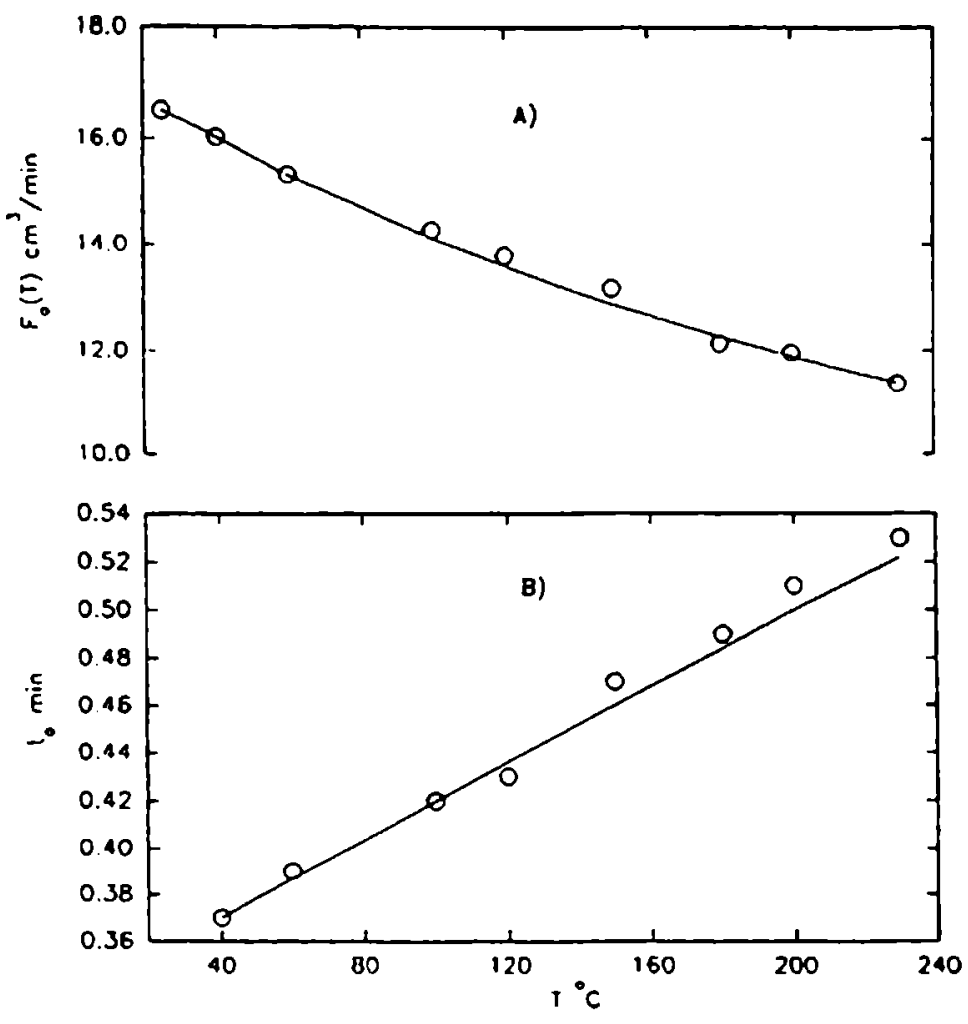

Fig. 6. Flow functions for the constant head pressure control (A) Fo(T) function. Column $120 \mathrm{~cm} \times 2 \mathrm{~mm}$ LD, filled with Gas Chrom $Q 80 / 100$ mesh, $5 \%$ OV-17. $P_{P}=1140$ and $P_{0}=760 \mathrm{mmHg}, F_{0}{ }^{\circ}=16.52 \mathrm{~cm}^{3} / \mathrm{min}, T^{\circ}=25^{\circ} \mathrm{C}$. Filled line calculated using Eq. (21). (B) $t_{0}(T)$ function Conditions as in $(A), T^{\circ}=40^{\circ} \mathrm{C}$ and $t_{0}^{\circ}=0.37 \mathrm{~min}$. Filled line calculated using Eq. (22).
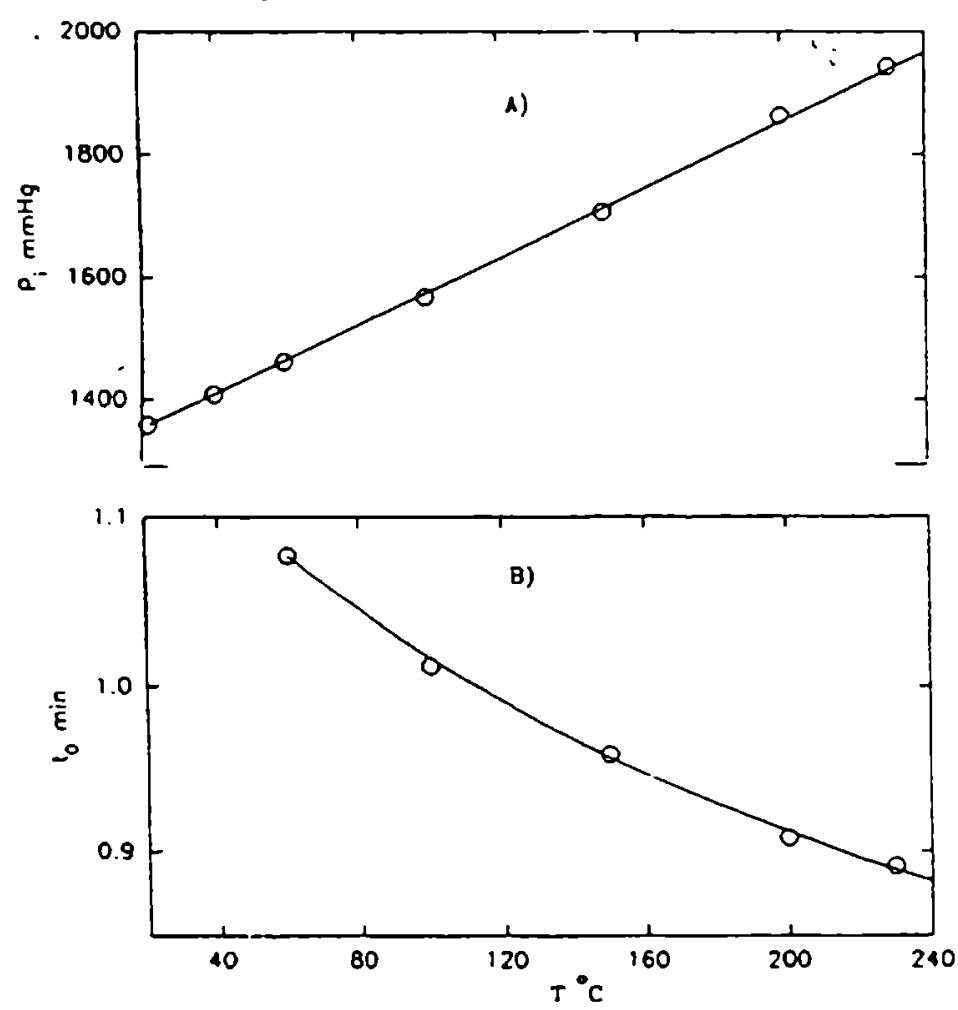

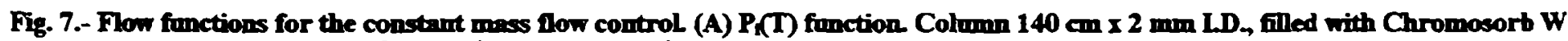
80/100, 5\% OV-17. $F_{0}=10.27 \mathrm{~cm}^{3} / \mathrm{min}, T^{\circ}=21.5^{\circ} \mathrm{C}$ and $P_{1}^{\circ}=1358 \mathrm{mmHg}$. Filled line calculated using Eq. (23). (B) $t(T)$ function, cohmm as in (A), $T^{0}=60^{\circ} \mathrm{C}, t_{0}^{\circ}=1.077 \mathrm{~min}$ and $P_{1}^{0}=1462 \mathrm{mmHg}$. Filled line calculated using Eq. (24).

Figure 7 shows the expected behavior pattern and the experimental results in this case. A electronic flow controller was not available, so a standard mechanical flow controller consisting in a needle valve/diaphragm operated valve combination, was employed. The Hewlett Packard 5880 chromatograph with the original controller was used with a $140 \mathrm{~cm}$ column filled with Chromosorb W 80/100 and 5\% OV-101. Conditions were selected to allow the system resemble the postulated behavior. Even with the relative low pressure drop column used and with flow rates as low as $10 \mathrm{c} . \mathrm{c} . / \mathrm{min}$, the best performance would have a $5 \%$ flow rate drift in a temperature interval of $200^{\circ} \mathrm{C}$. Obviously, with a higher pressure drop column or 
a higher flow rate demand the device was not able to comply with the duty. Shown experimental data were corrected for the observed flow rate drift.

\section{The programmable head pressure}

Recent advances in computer controlled head pressure have been described with some detail [25]. The performance of commercially available linear programmable head pressure chromatographs has been evaluated [26].

Pressure program is coupled to temperature program to obtain the desired optimized performance. Both programs are given by the respective explicit functions : $T=f(t)$, and $P=E(t)$. Then:

$$
\frac{\mathrm{dP}}{\mathrm{dT}}=\frac{\mathrm{E}^{\prime}}{\mathrm{f}^{\prime}}
$$

Integrating between the initial values of the programs and a generic point:

$$
P(T)=P^{0}+\int_{T^{0}}^{T} \frac{E^{\prime} d T}{f^{\prime}}
$$

For example, if temperature and pressure programs are linear and $\mathrm{P}_{\mathrm{o}}$ is held constant, namely:

$$
\begin{aligned}
& T=T^{0}+r_{T} t \\
& P_{i}=P_{i}^{0}+r_{P} t
\end{aligned}
$$

Then using (25):

$$
P_{i}(T)=P_{i}^{0}+\frac{I_{P}}{I_{T}}\left(T-T^{0}\right)
$$

In this case eq.(9) delivers:

$$
F_{0}(T)=F_{0}^{0}\left(\frac{T}{T^{0}}\right)^{-N} \frac{\left\{\left[P_{i}^{0}+\frac{r_{P}}{r_{T}}\left(T-T^{0}\right)\right]^{2}-P_{0}^{2}\right\}}{\left(P_{i}^{0^{2}}-P_{0}^{2}\right)}
$$

and from (12):

$$
t_{0}(T)=t_{0}^{0} \frac{\left(P_{i}^{0^{2}}-P_{0}^{2}\right)^{2}}{\left(P_{i}^{0^{3}}-P_{0}^{3}\right)}\left(\frac{T}{T^{0}}\right)^{N} \frac{\left\{\left[P_{i}^{0}+\frac{r_{P}}{r_{T}}\left(T-T^{0}\right)\right]^{\beta}-P_{o}^{3}\right\}}{\left\{\left[P_{i}^{0}+\frac{r_{P}}{r_{T}}\left(T-T^{0}\right)\right]^{R}-P_{0}^{2}\right\}^{2}}
$$


A programmable pressure control system was not available but it's function could be simulated by fixing the column's inlet pressure manually at each temperature, using the system described in section "The needle valve flow control", increasing pressure at a rate of $\mathrm{r}_{\mathrm{P}} / \mathrm{r}_{\mathrm{T}}=1.5 \mathrm{mmHg} / \mathrm{C}$. In Figure 8 are represented the experimental data and the calculated curves by means of eqs. (27) and (28).

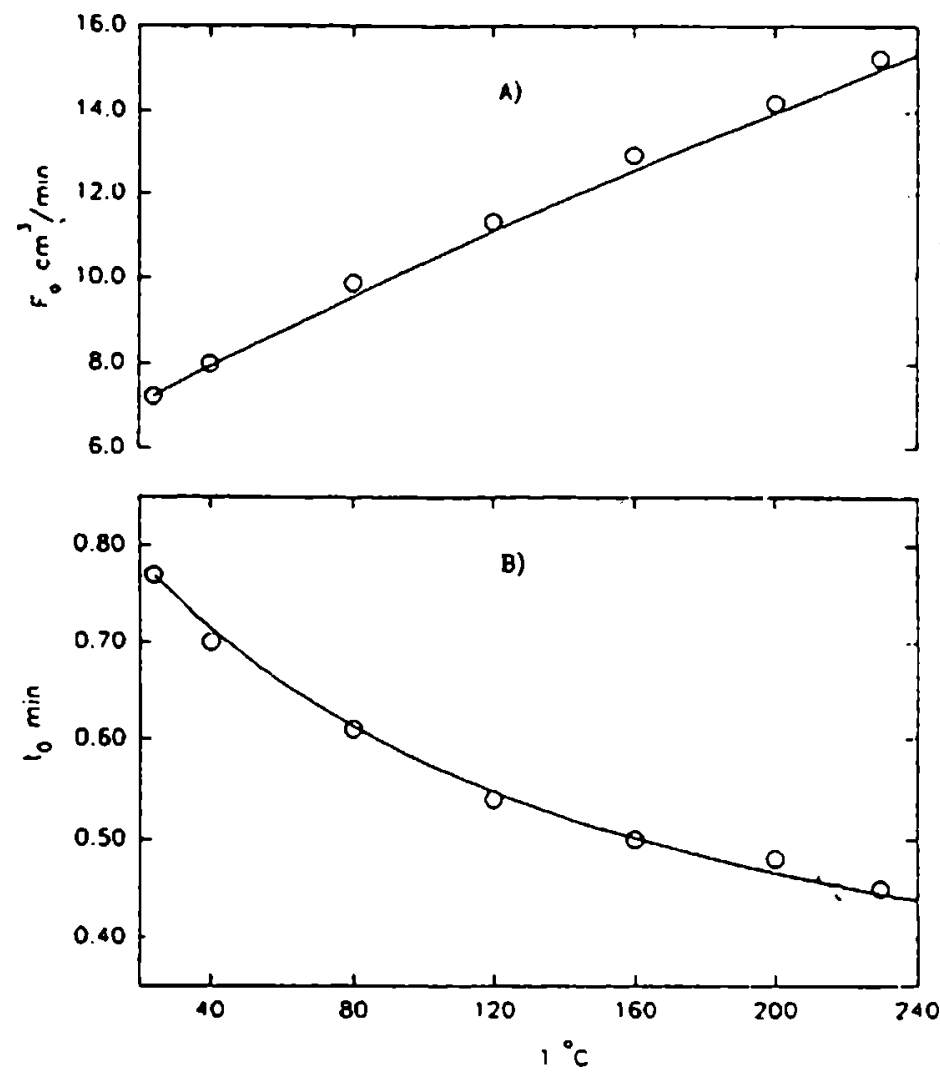

Fig. 8. - Flow functions for a linear head pressure program (A) $F_{0}(T)$ function $R_{p} / r_{T}=1.5 \mathrm{mmHg} / \mathrm{C}_{,} T^{0}=24^{\circ} \mathrm{C}, P_{1}^{0}=956 \mathrm{mmHg}$ and $F_{0}{ }^{0}=7.23 \mathrm{~cm}^{3} / \mathrm{min}$. Filled line calculated using Eq. (27). (B) to (T) function. Condritions as in (A) and $t_{0}^{\circ}=0.77 \mathrm{~min}$. Filled line calcalated using Eq. (28).

\section{CONCLUSIONS}

Analytical expressions of $t_{0}(T)$ have been displayed for four flow control modes : needle valve system, constant inlet pressure, constant mass flow and linear programmed head pressure. All are applicable to packed or capillary columns. The method being used assumes that geometric parameters $\mathrm{V}_{0}$ and $\mathrm{L} / \mathrm{AB}$ remain constant with temperature, hypothesis that as shown in section 3 would not have major consequences under practical chromatographic conditions. In this paper $t_{0}(T)$ was determined always by estimating column's constant $C_{t}$ from a single point (from initial dead time, inlet and outlet pressure, and temperature, using eq.(13)), which a priori could be appreciated as a inaccurate procedure. One may fairly think that a more precise estimation of column's constant should be conducted, e.g. by linear regression applying eq. (12). Contrasting calculated and experimental data showed that the applied procedure suffices for predicting $\mathrm{t}_{0}(\mathrm{~T})$ with reasonable precision for practical purposes as retention simulation in PTGC. This, obviously, is consequence of the fact that the parameters $P_{i}^{0}, P_{0}, T^{0}$ and $t_{0}^{0}$ can be measured accurately. The application of the expressions of $t_{0}(T)$ to retention simulation is a matter of a related work [27]. 


\section{ACKNOWLEDGEMENT}

This work was sponsored by the Consejo Nacional de Investigaciones Cientificas y Técnicas and the Comisión de Investigaciones Científicas de la Provincia de Buenos Aires.

\section{REFERENCES}

[1] Giddings, J.C.- J. Chromatogr., 4, 11 (1960).

[2] Dal Nogare, S.; Langlois, W.E.- Anal. Chem., 32, 767 (1960).

[3] Habgood, H.W.; Harris, W.E.- Anal. Chem., 32, 450 (1960).

[4] Habgood, H.W.; Harris, W.E.- Programmed Temperature Gas Chromatography, J. Wiley and Sons, N.Y. (1966).

[5] Rowan, R-Anal. Chem., 33, 510 (1961).

[6] Zhang, J.Y.; Wang, G.M.; Quian, R.- J. Chromatogr., 521, 71 (1990).

[7] Shrotri, P.Y.; Mokashi, A; Mukesh D.- J. Chromatogr., 387, 399 (1987).

[8] Conder, J.R. J. Chromatogr., 248, 1 (1982).

[9] F.R. González and AM. Nardillo, unpublished.

[10] Grant, D.W.; Hollis, M.G.- J. Chromatogr., 158, 3 (1978).

[11] Curvers, J.; Rijks, J.; Cramers, C.; Knauss, K.; Larson, P.- J. High. Resolut. Chromatogr. Chromatogr. Commun., 8, 607 (1985).

[12] Bautz, D.E.; Dolan, J.W.; Snyder, L.R.- J. Chromatogr., 541, 1 (1991).

[13] Gerbino, T.C.; Castello, G., Pettinati, U.- J. Chromatogr., 634, 338 (1993).

[14] Castello, G.; Moretti, P.; Vezzani, S.- J. Chromatogr., 635, 103 (1993).

[15] Horlick, G.; Harris, W.E.; Habgood, H.W.- Anal. Chem., 38, 7 (1966).

[16] Bird, R.B.; Stewart, W.E.; Lightfoot, E.N.- Transport Phenomena, J. Wiley and Sons, N.Y. (1964).

[17] Guiochon, G.- Chromatogr. Rev., 8, 1 (1966).

[18] Cramers, C.; Rijks, J.; Schutjes, C.P.M.- Chromatographia, 14, 439 (1981).

[19] Ettre, L.S.- Chromatographia, 18, 243 (1984).

[20] Blumberg, L.M.- Chromatographia, 41, 15 (1995).

[21] Touloukian, Y.S.- Thermophysical Properties of Matter, Vol. 12, IFI, Plenum, N.Y. (1975).

[22] Knox, J.H.- J. Chromatogr. Sci., 15, 352 (1977).

[23] Cowper, C.J.; De Rose, A.J.- The Analysis of Gases by Chromatography, Pergamon Press, N.Y. (1985).

[24] Wicar, S. - J. Chromatogr., 295, 395 (1984).

[25] Hinshaw, J.V.- LC GC, 13, 792 (1995).

[26] Hermann, B.W.; Freed, L.M.; Thompson, M.Q.; Phillips, RJ; Klein, K.J.; Snyder, W.D.- J. High. Res. Chromatogr. Instrum., 13, 361 (1990).

[27] González, F.R; Nardillo, AM.- Submitted for publication. 